\title{
Factors Analysis Affecting Lateral Canal Benign Paroxysmal Positional Vertigo
}

\author{
Chul-Seung Kim ${ }^{1}$, Hee-Young Choi $^{2}$, Pil-Seung Kwon ${ }^{3}$, Eun-Pyo Lee ${ }^{1}$ and Choong-Won Seo ${ }^{1}$ \\ ${ }^{1}$ Department of Biomedical Laboratory Science, Seonam University, Namwon 590-711, Korea \\ ${ }^{2}$ Department of Hospital Administration, Seonam University, Namwon 590-711, Korea \\ ${ }^{3}$ Department of Clinical Laboratory Science, Wonkwang Health Science University, Iksan 570-750, Korea
}

\begin{abstract}
Lateral canal benign paroxysmal vertigo (BPPV) causing dizziness is a common cause is not found while continuing to appeal for vertigo is a typical disease. It is characterized by acute stand up, brief and rotatory vertigo attacks provoked by change in head position. Treatment requires only one treatment visit in most patients. However, there are significant numbers of patients who require multiple treatment visits for relief. The purpose of this study benign paroxysmal positional vertigo treatment of type affect is to analyze the cause. Dizziness and vertigo patient's in patients admitted to the dizziness center of lateral canal benign paroxysmal positional vertigo were classified. In patients with lateral canal benign paroxysmal positional vertigo and accompanying lateral 15 treatment affects disease were investigated. March 2008 to November 2010 lateral canal benign paroxysmal positional vertigo 166 people cure rate of patients was investigated. First time the success rate of $74.1 \%$, twice times the success rate of $12.0 \%$, three times the success rate of $9.6 \%$, more than three times the success rate was $4.2 \%$. Affecting factor treatment of benign paroxysmal positional vertigo in post-traumatic, medicine disease, headache, cerebral infarction, small vessel disease, vestibulopathy, $(p<0.05)$. Statistical analysis using SPSS (version 12K) in coefficient measure through descriptive statistical of cross table.
\end{abstract}

Keywords: Benign paroxysmal vertigo, Canalith repositioning procedures, Post-traumatic, vestibulopathy, Headache

This is an Open Access article distributed under the terms of the Creative Commons Attribution Non-Commercial License (http://creativecommons.org/licenses/by-nc/3.0) which permits unrestricted non-commercial use, distribution, and reproduction in any medium, provided the original work is properly cited.

Copyright $(2015$ The Korean Society for Clinical Laboratory Science. All rights reserved.
Corresponding author: Choong-Won Seo Department of Biomedical Laboratory Science, Seonam University, Namwon 590-711, Korea Tel: 82-42-364-3711

E-mail: seo3711@naver.com

Received: February 27, 2015

Revised: March 18, 2015

Accepted: March 19, 2015

\section{서 론}

어지럼증을 일으키는 질환은 빈혈, 기립성저혈압, 뇌질환 등 여 러 가지 요인이 존재하지만 귀쪽반고리관에 이석이 발생하여 평형 반이 약화되어 어지럼증을 발생되는 양성발작성 두위현기증이 많 이 발생하고 있다. 그러나 단순히 빈혈이라고 생각하고 약물치료만 할 경우 계속적인 어지럼증이 존재하게 된다. 가쪽반고리관은 다른 반고리관 양성발작성 두위현기증 보다 증상이 심하고 눕거나 일어 날 때 보다는 누운 자세나 심하면 선 자세에서도 고개를 좌우로 돌 릴 때 증상이 생겨날 수 있다(Dix와 Hallpike, 1952). 양성발작성 두위현기증 양상으로 어지럼을 가지고 있는 환자가 Dix and Hallpike 검사 상 뚜렷한 어지럼이나 눈떨림이 관찰되지 않는다면 가쪽반고리관 양성발작성 두위현기증을 의심할 수 있으며, 머리회 전 검사를 이용하여 진단에 도움을 받을 수 있다(Bhattacharyya
등, 2009). 가장 널리 쓰이는 방법으로 누운 자세에서 고개를 건강 한 쪽으로 빠르게(0.5초 이내) $90^{\circ}$ 회전시킨 후 눈떨림이 소실될 때 까지 30 60 초간 자세를 유지하고 이후 $90^{\circ}$ 씩 $270^{\circ}$ 까지 머리를 회전시켜 이석이 팽대부릉정의 반대 방향으로 가쪽반고리관으로 빠 져나가게 하는 방법이다(Lempert와 Tiel-Wilck, 1996). Barbecue maneuver는 Lempert 방법과 달리 머리를 $360^{\circ}$ 회전시키며 각 단 계 별로 머리 자세를 30 60 초간 유지한다. 이러한 방법으로 눈떨 림이 소실될 때까지 계속하여 1주 이내에 $75 \%$ 의 치유를 보였다는 보고가 있으며, 이석 정복술을 시행하지 않은 경우 52\%에서 1 5 개월간 증상이 지속되었다는 보고가 있다(Casani 등, 2002).

\section{재료 및 방법}

치료 횟수와 양성발작성 두위현기증과 동반된 질환에 의한 어지 
럼증 지속여부의 상관관계를 알아보기 위해 2008년 3월부터 2010 년 11월까지 가쪽반고리관 양성발작성 두위현기증 환자 166명을 대상으로 연구와 관련하여 서면과 유선상으로 동의를 구한 후 후향 적 의무기록을 통해 이석정복술의 치료효과를 조사하였다. 비디오 눈떨림 검사를 시행하여 가쪽반고리관형으로 진단된 경우 Barbecue maneuver를 각각 시행하였다. 검사 시 몸에서의 유지시간은 눈떨 림이 사라지거나 10 30초 정도로 하였으며, 대부분의 경우 1 회의 정복술을 시행하였다. 시행한 당일에는 취침 전까지 눕지 않도록 하고, 취침 시에는 베개를 높이 하고 취침을 하도록 권고하였다. 환 자는 2 일에서 1 2주후에 다시 내원하여 어지럼증의 주관적 증상 이 있는지 여부를 확인하여 비디오 눈떨림 검사를 통해 눈떨림 유 무를 확인하여 치료 횟수를 산정하였다. 특징적인 눈떨림이 소실된 경우를 치료 성공으로 보았다. 만약 주관적 어지럼증이 존재하고 비디오 눈떨림 검사 상 눈떨림이 남아있는 경우는 다시 이석 정복 술을 시행하였다. 입원환자의 경우 매일 어지럼증 유무를 확인하여 눈떨림이 소실될 때까지 이석 정복술을 시행하였다. 임상양상 분석 은 환자군의 가쪽반고리관의 치료성적분석, 이석 정복술 후 치료 실패요인에 대한 분석을 시행하였다. 관련인자별로 외상유무, 뇌 쪽 질환유무, 메니에르씨병 및 두통, 편두통, 중이염, 안뜰신경염, 당뇨, 고혈압의 유무, 치료 후 증상의 지속시간이 치료성적에 미치 는 영향을 통계적 분석인 SPSS (version $12 \mathrm{~K}$ )를 이용하여 기술통 계량(descriptive statistics)에서 교차분석(cross table)을 통해람 다 $(\lambda)$ 값을 통해 근사유의확률을 구했다. 근사유의확률은 $p<0.05$ 미 만일 경우 통계적으로 유의하다고 판정하였다.

Table 1. Disease accompanied lateral canal benign paroxysmal positional vertigo

\begin{tabular}{lcccc}
\hline \multicolumn{1}{c}{ Diagnosis } & Rt LC & Lt LC & Total (\%) & $p$ value \\
\hline Idiopathic & $48(28.9)$ & $48(28.9)$ & $96(57.8)$ & 0.002 \\
Post-traumatic & $5(3.0)$ & $3(1.8)$ & $8(4.8)$ & 0.005 \\
Medicine disease & $7(4.2)$ & $1(0.6)$ & $8(4.8)$ & 0.004 \\
Tinnitus & 0 & $1(0.6)$ & $1(0.6)$ & 0.001 \\
Meniere's disease & $1(0.6)$ & 0 & $1(0.6)$ & 0.034 \\
Otitis media & 0 & $1(0.6)$ & $1(0.6)$ & 0.109 \\
Migraine & 0 & $2(1.2)$ & $2(1.2)$ & 0.034 \\
Headache & $8(4.8)$ & $3(1.8)$ & $11(6.6)$ & 0.003 \\
Small vessel & $5(0.9)$ & $5(0.9)$ & $10(6.0)$ & 0.004 \\
Cerebral infarction & $3(0.4)$ & $4(0.8)$ & $7(4.2)$ & 0.005 \\
VBI & $2(1.2)$ & $2(1.2)$ & $4(2.4)$ & 0.034 \\
Cerebral hemorrhage & 0 & $2(1.2)$ & $2(1.2)$ & 0.034 \\
Cerevascular disease & 0 & $1(0.6)$ & $1(0.6)$ & 0.204 \\
Brain lesion & $1(0.6)$ & 0 & $1(0.6)$ & 0.107 \\
Vestibulo-pathy & $3(1.8)$ & $4(2.4)$ & $7(4.2)$ & 0.007 \\
The others & $4(2.4)$ & $2(1.2)$ & $6(3.6)$ & 0.000 \\
Total & $87(52.4)$ & $79(47.6)$ & 166 & 0.000 \\
\hline
\end{tabular}

\section{결 과}

\section{1. 가쪽 양성발작성 두위현기증과 동반되는 질환}

가쪽 양성발작성 두위현기증으로 진단된 환자에 대하여 후향적 의무기록을 통해 증상을 유발시킬 수 있는 인자를 살펴보았다. 원 인이 미상인 경우가 96례(57.8\%), 두통을 동반한 경우도 11 례 (6.6\%), small vessel disease (작은 혈관질환-뇌의 혈관이 좁아진 환자)가 10 례(4.5\%), 외상인 경우 8례(4.8\%), 고혈압, 당뇨, 신부전 등 내과적인 질환을 동반한 경우가 8례(4.82\%), 뇌경색환자가 7례 (4.2\%), 한쪽 안뜰기능 저하가 보이는 경우는 7례(4.2\%)등 평형반 의 약화를 일으켜 이석을 유발시킬 수 있는 귀쪽 질환도 보였으며, 중추성 질환도 동반되었다. 통계적으로 중이염 및 뇌경색을 제외한 뇌질환을 고 유의한 상관관계를 보였다. 양성발작성 두위현기증과 관련성이 있는 질환은 외상 후, 내과적 질환, 뇌혈관 좁아짐, 뇌경 색, 안뜰신경염, 두통 등이 유의성 있게 많은 비율을 차지했다 (Table 1).

\section{2. 가쪽 반고리관형 양성발작성 두위현기증 치료횟수}

가쪽반고리관형 양성발작성 두위현기증으로 진단된 경우 이석 정복술인 Barbecue maneuver으로 치료 시 1회 치료율이 74.1\%, 2회 치료율이 $12.0 \%, 3$ 회 치료율이 9.6\%이고 3회 이상 계속 치료 한 경우는 $4.2 \%$ 에 불과했다. 치료율은 오른쪽이 약간 높았지만 거 의 비슷한 것을 볼 수 있다. 이석정복술은 정확한 병명진단 후 병명 에 따른 정확한 치료와 환자의 도움이 필요하다. 그러나 치료가 성 공적으로 이루어 졌다 하여도 여러 가지 인자들에 의해서 이석막의 이석이 떨어져 나와 반고리관내에 들어가게 되면 평형반이 약화되 어 계속적인 재발이 이루어 질 수 있다(Table 2).

\section{3. 가쪽 반고리관형 양성발작성 두위현기증 치료에 영향을 미치는 인자 분석}

가쪽반고리관형 양성발작성 두위현기증의 이석 정복술 치료 횟 수에 영향을 주는 인자들을 분석해보면 오른쪽 부분에서 1회 치료 성공률은 특발성이 $50.0 \%$ 로 가장 높았고, 내과적 질환, 안뜰신경

Table 2. The number of treatment lateral canal benign paroxysmal positional vertigo

\begin{tabular}{llccc}
\hline & & Rt LC & Lt LC & Total \\
& & BPPV & BPPV & \\
\hline Treatment & 1 & $65(39.2)$ & $58(35.5)$ & $123(74.1)$ \\
visits/No. of & 2 & $12(7.2)$ & $8(4.8)$ & $20(12.0)$ \\
patients (\%) & 3 & $7(4.2)$ & $9(5.4)$ & $16(9.6)$ \\
& 3 More than & $3(1.8)$ & $4(2.4)$ & $7(4.2)$ \\
& Total (\%) & $87(52.4)$ & $79(47.6)$ & $166(100)$ \\
& $p$ value & 0.004 & 0.006 & 0.004 \\
\hline
\end{tabular}


Table 3. Factor of effect Lateral canal Benign paroxysmal vertigo treatment

\begin{tabular}{|c|c|c|c|c|c|c|}
\hline \multirow{2}{*}{ Diagnosis } & \multicolumn{4}{|c|}{ Treatment visits/No. of patients (\%) } & \multirow{2}{*}{ Total (\%) } & \multirow{2}{*}{$p$ value } \\
\hline & 1 & 2 & 3 & 3 more tnan & & \\
\hline Idiopathic & $83(50.0)$ & $9(5.4)$ & $4(2.4)$ & 0 & $96(57.8)$ & 0,002 \\
\hline Post-traumatic & $5(3.0)$ & $1(0.6)$ & $1(0.6)$ & $1(0.6)$ & $8(4.8)$ & 0.068 \\
\hline Medicine disease & $6(3.6)$ & $1(0.6)$ & 0 & $1(0.6)$ & $8(4.8)$ & 0.006 \\
\hline Meniere's disease & 0 & $1(0.6)$ & 0 & 0 & $1(0.6)$ & 0.264 \\
\hline Tinnitus & $1(0.6)$ & 0 & 0 & 0 & $1(0.6)$ & 0.264 \\
\hline Headache & $8(4.8)$ & $2(1.2)$ & $1(0.6)$ & 0 & $11(6.6)$ & 0.002 \\
\hline Otitis media & 0 & 0 & 0 & $1(0.6)$ & $1(0.6)$ & 0.264 \\
\hline Migraine & $2(1.2)$ & 0 & 0 & 0 & $2(1.2)$ & 0.264 \\
\hline Small vessel disease & $4(2.4)$ & $3(1.8)$ & $2(1.2)$ & $1(0.6)$ & $10(6.0)$ & 0.002 \\
\hline Cerebral infarction & $2(1.2)$ & 0 & $4(2.4)$ & $1(0.6)$ & $7(4.2)$ & 0.005 \\
\hline $\mathrm{VBI}$ & $4(2.4)$ & 0 & 0 & 0 & $4(2.4)$ & 0.264 \\
\hline Cerevascularvdisease & 0 & 0 & 0 & $1(0.6)$ & $1(0.6)$ & 0.264 \\
\hline Brain lesion & 0 & 0 & $1(0.6)$ & 0 & $1(0.6)$ & 0.264 \\
\hline Vestibulopathy & $2(1.2)$ & $3(1.8)$ & 0 & $2(1.2)$ & $7(4.2)$ & 0.006 \\
\hline Cerebral hemorrhage & 0 & 0 & $2(1.2)$ & 0 & $2(1.2)$ & 0.264 \\
\hline The others & $6(3.6)$ & 0 & 0 & 0 & $6(3.6)$ & 0.264 \\
\hline Total & $123(74.1)$ & $20(12.1)$ & $16(9.6)$ & $7(4.2)$ & $166(100)$ & 0.008 \\
\hline
\end{tabular}

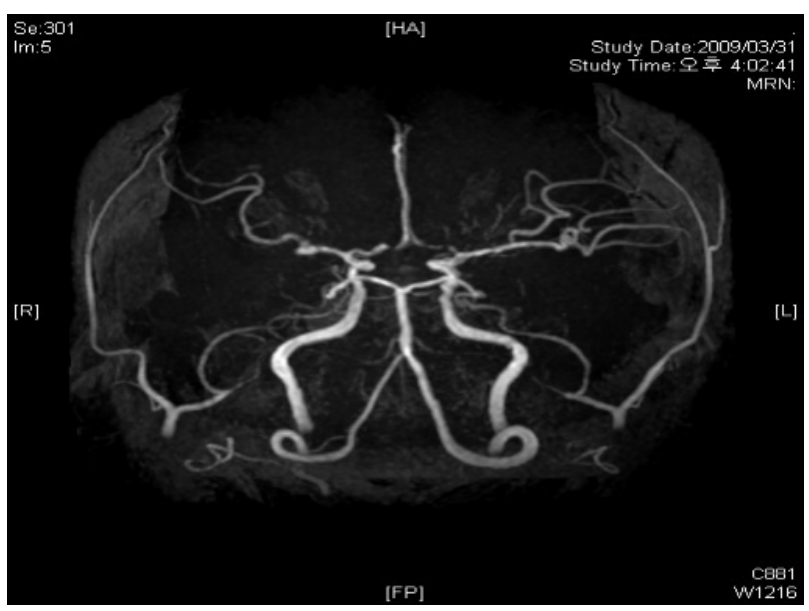

Fig. 1. Occlusion and stenosis of middle cerebral artery in magnetic resonance angiography Luminal irregularity and narrowing of both middle cerebral artery. Decreased vascularity of right middle cerebral artery branches. Focal stenosis of right posterior cerebral artery and both $A_{1}$.

염, 두통, 작은 혈관질환 등이 1 2회 치료 성공률이 높았고 이석정 복술 실패로 인한 재발확률도 떨어진 것을 볼 수 있었다. 3 회 이상 의 어지럼증이 지속된 경우가 내과적 질환, 안뜰신경염, 작은 혈관 질환, 뇌경색 등이 있었다. 통계적으로 메니에르씨병, 이명, 중이 염, 편두통, 척추기저동맥 순화분전, 뇌혈관질환, 뇌질환, 뇌출혈를 제외하고 양성발작성 두위현기증과 연관된 인자와 치료횟수가 $p<0.05$ 로 상관관계가 있었다(Table 3). 가쪽반고리관형 양성발 작성 두위현기증의 치료가 지연되는 원인이 단순한 특발성도 있었 지만 주로 안뜰계와 관련된 부분의 질환에 의해 평형반의 기능의
약화로 발생한 것으로 보인다. 뇌질환인 경우 경막외출혈 및 수막 염과 뇌혈관 직경의 감소로 인해 안뜰계로 유입되는 혈류량의 감소 로 인하여 반고리관의 기능이 약화되어 반고리관이 정복되더라도 이 질환을 치료하지 않으면 계속적으로 어지럼을 동반할 수 있다. 뇌혈관 촬영을 판독한 결과 양쪽 중대뇌 동맥 직경감소와 오른쪽 중대뇌 동맥부분의 혈류량이 현저히 감소하였고 오른쪽 후대뇌 동 맥과 양쪽 전대뇌 동맥이 전체적으로 협착소견을 보인 환자로서 오 른쪽 가쪽반고리관 양성발작성 두위현기증이 유발되었고 3회에 걸쳐 이석 정복술을 통해 이석치료를 시행 하였지만 뇌경색질환으 로 인해 계속 어지럼증을 호소하였다(Fig. 1).

\section{고 찰}

흔히 어지럼증이 유발되면 빈혈, 뇌경색, 기립성 저혈압 등을 의 심한다. 그러나, 갑자기 일어나거나 옆으로 누울 때 빙빙돌면서 오 심이 나타나고 심하면 구토를 동반하는 경우가 있다. 이러한 질환 을 단순한 빈혈로 판단하고 간과한 경우에는 계속적으로 어지럼증 이 나타날 수 있다. 이러한 현상을 방지하기 위하여 어지럼증이 호 소하는 환자를 대상으로 자세한 문진을 한 후 눈떨림 검사로 반고 리관 약화 위치를 파악한 후 적절한 이석정복술을 통해 어지럼증을 치료할 수 있다(Byun과 Yun, 2010). 가쪽반고리관 양성발작성 두 위현기증의 이석정복술 방법은 머리를 $360^{\circ}$ 회전계속한 결과 1 주 이내에 $75 \%$ 의 치유를 보였다는 보고가 있으며(Macias 등, 2000), 이석정복술을 시행하지 않은 경우에는 $52 \%$ 에서 1 5 개월간 증상 이 지속되었다는 보고가 있다(Casani 등, 2002). 이러한 이석 정복 
술을 통해 이석이 제거되면 치료 즉시 어지럼증이 소실되지만 양성 발작성 두위현기증과 동반되어 있는 질병에 의해 이석정복술 치료 횟수도 증가하게 된다(Lee, 2001). 이석정복술의 결과에 영향을 주 는 연구보고는 많지 않다. 이석정복술의 1회 치료로 실패한 경우는 $12 \%$ 에서 $56 \%$ 로 보고되고 있다. 본 연구에서는 1 회 치료로 회복된 예는 74.1\%로 다른 보고(Macias 등, 2000; Furman과 Cass, 1999) 와 유사하게 높은 치료율을 보이고 있다. Chang (2005)은 외상 후 반고리관의 변화로 인해서 이석 정복술의 횟수가 증가하였다. SO (2005)는 외상이 있는 환자와 없는 환자를 비교했을 때 횔씬 더 외 상이 있는 환자의 치료횟수가 증가한다는 것을 볼 수 있다. 외상이 평형반에 영향을 주어 약화시켜서 이석의 발생 횟수의 증가하였다 고 보고하였다. 이석정복술 시술 당일 취침 전까지 눕지 않도록 하 고, 취침 시에는 병변의 반대쪽으로 눕게 하였고 다음 날부터 정상 적인 생활을 하도록 주의를 시켰다. 가쪽 양성발작성 두위현기증과 동반되어 나타나는 질환은 외상 후, 내과적 질환, 뇌혈관 좁아짐, 뇌 경색, 안뜰신경염, 두통 등이 유의하게 상관관계를 보였다(Table 1). 가쪽 반고리관 양성발작성 두위현기증의 치료횟수는 1 회 치료 성공률이 $74.1 \%$ 로 유의성 있는 결과를 보였다. So (2005)는 치료 에 영향을 주는 인자로 외상, 중이염, 안뜰신경염 등을 제시하였고 이 연구에서는 15 개 인자와 양성발작성 두위현기증 치료횟수와의 연관성을 조사한 결과 내과적 질환, 두통, 작은혈관질환, 안뜰신경 염, 뇌경색 등이 상관관계가 있었다(Table 3). 다시 살펴보면 가쪽 양성발작성 두위현기증과 연관성이 있는 15 개 인자에 대하여 치료 횟수와의 연관성을 조사한 결과 가쪽양성돌발성 두위현기증과 동 반된 질환이 사라지면서 어지럼증이 남아 있는지 여부를 살펴보았 다. 어지럼증을 일으키고 치료에 영향을 미치는 인자들에 의해서 치료 횟수가 증가되는 것을 볼 수 있었다. 특히 외상 후, 메니에르씨 병, 두통, 작은혈관질환, 뇌경색, 안뜰신경염의 질환들이 이석정복 술의 치료횟수를 증가시키는 것을 볼 수 있었다. 외상 후, 안뜰신경 염 등은 치료횟수도 증가했지만 1 회 치료 성공률도 높았고 두통은, 대부분 1 회에 치료가 되면 두통이 사라지는 경우가 많았다. 위에서 열거한 질환들이 치유가 되면 어지럼증이 사라지는 경우가 많기 때 문에 정확한 병명진단과 반고리관의 위치 파악을 통해 이석정복술 을 시행한다면 어지럼증이 훨씬 더 감소할 것이다. 이석정복술을 통해 이석을 반고리관내에서 제거하더라도 동반된 질환을 치료 못 할 경우 이 인자에 의해 평형반이 약화되어 다시 이석이 생길 수 있 으므로 이러한 인자들을 제거하게 되면 이석정복술의 성공확률이 높아 질 수 있다. 어지럼증의 정확한 검사시행과 치료방법의 선택
이 많은 환자들의 어지럼증에 대한 공포에서 벗어나게 해 줄 것으 로 사료된다고 보고하였고(Kim과 Park, 2008), 뇌질환이나 뇌종 양이 있는 환자에서 반측성 안면경련증상이 뇌종양 때문인지, 뇌종 양과 별개로 안면신경 주변의 동맥혈관에 의한 것인지는 정확하게 파악하기 어렵다고 보고하였고(Park 등, 2013), 이 외에 수직반고 리관 양성발작성두위현기증, 안뜰신경염 등 어지럼증을 일으키는 여러 요인들도 간과해서는 안 될 것으로 보인다.

\section{Acknowledgements: None}

Funding: None

Conflict of interest: None

\section{References}

1. Bhattacharyya N, Baugh RF, Orvidas L, Barrs D, Bronston LJ, Cass S. Clinical practice guideline: benign paroxysmal positional vertigo. Otolaryngol Head Neck Surg. 2009, 5(4):47-81.

2. Bhattacharyya N, Baugh RF, Orvidas L, Barrs D, Bronston LJ, Cass S. Clinical practice guideline: benign paroxysmal positional vertigo. Otolaryngol Head Neck Surg. 2009, 5(4):47-81.

3. Byun JY, Yun EW. Diagnosis and Treatment of benign paroxysmal positional vertigo. The korean Balance socity. 2010, 9:55-63.

4. Casani AP, Vannucci G, Fattori B, Berrettini S. The treatment of horizontal canal positional vertigo, our experience in 66 cases. Otol Neurotol. 2002, 112:172-178.

5. Chang $\mathrm{CH}$. The Analysis of Post-Tra umatic benign paroxysmal positional vertigo. The korean Balance socity. 2005, 4(1):17-25.

6. Dix MR, Hallpike CS. The pathology symptomatology and diagnosis of certain common disorders of the vestibular system. Ann Otol Rhinol Laryngol. 1952, 61:987-1016.

7. Park SG, Hyun SC, Lim SH, Park CW, Park JW, Kim DJ, Kim KE, Kim BG. Hemifacial Spasm Caused by Brain Tumor. Korean J Clin Lab Sci. 2013, 45(3):124-129

8. Furman JM, Cass SP. Benign paroxysmal positional vertigo. $N$ Engl J Med. 1999, 341:1590-1596.

9. Kim CS, Park SM. Pathogensis of Benign Paroxysmal Positional Vertigo (BPPV). Korean J Clin Lab Sci. 2008, 40(1):62-70.

10. Lee GK. Dizziness. Dan-kuk press. 2001, 2(6):136-137.

11. Lempert T, Tiel-Wilck KA. position -al maneuver for treatment semicircular canal benign paroxysmal positional vertigo. Laryngosc cope. 1996, 106:476-478.

12. Macias JD, Lambert T, Massingale S. Variables affecting treatment in benign paroxysml positional vertigo. Laryngoscope. 2000, 110:1921-1924.

13. So YK. Factor Affecting Treatments of benign paroxysmal positional vertigo. The korean Balance socity. 2005, 4(2):235-236. 